\title{
Radiation-induced osteosarcoma of the skull base after radiation therapy in a patient with nasopharyngeal carcinoma: a case report and review of the literature
}

\author{
Yassine Echchikhi, Hasna Loughlimi, Asmae Touil, Tayeb Kebdani and Noureddine Benjaafar
}

\begin{abstract}
Background: Radiation-induced osteosarcomas are a recognized complication of radiation therapy. Owing to the fact that it is rare, publications on radiation-induced osteosarcoma of the skull base are limited to a small series and some case reports.

Case presentation: We describe a rare case of a patient with a skull base radiation-induced osteosarcoma treated 11 years before with ionizing radiation for an undifferentiated carcinoma of the nasopharynx. The patient was treated with chemotherapy alone, but he died after the third cycle.

Conclusions: Radiation-induced osteosarcoma of the skull base after treatment of nasopharyngeal carcinoma is a very rare but very aggressive complication with a poor prognosis. Chemotherapy gives bad results, and regular followup of treated patients should be considered.
\end{abstract}

Keywords: Osteosarcoma, Skull, Radiotherapy, Nasopharynx, Chemotherapy, Pathogenesis

\section{Background}

Radiation-induced osteosarcomas are rare clinical entities that are recognized as a complication of radiation therapy and are associated with a poor prognosis. Their incidence ranges from $0.01 \%$ to $0.03 \%$ of all irradiated patients $[1,2]$ and $5.5 \%$ of all osteosarcomas [2]. This incidence could increase in the future because radiation therapy has become more common and developed, and patient survival has improved. Reports of radiation-induced osteosarcoma of the skull base are limited to a small series and some case reports. In this report, we describe a very rare case of skull base radiation-induced osteosarcoma in a patient treated with ionizing radiation for undifferentiated carcinoma of the nasopharynx.

\section{Case presentation}

A 29-year-old Moroccan man presented to our hospital with a 6-month history of headache in his left skull,

\footnotetext{
* Correspondence: eyassine12@hotmail.com

Department of Radiation Oncology, National Institute of Oncology, University

Mohamed 5, Ibn Sina Center, Allal El Fassi Boulevard, Rabat, Morocco
}

associated with homolateral facial pain, numbness, diplopia, exophthalmia, eye watering, and an episode of epistaxis. Eleven years before, he had received radiotherapy for undifferentiated carcinoma of the nasopharynx, initially classified as T1N1M0. The radiation dose he had received was $70 \mathrm{~Gy}$ in 35 fractions delivered using the classic 3-fields technique (2 lateral opposed fields abutted to an anterior low-neck field). This technique had been applied during the previous 20 years because it seemed to be the simplest.

The patient's physical examination revealed a left ptosis, hemifacial edema, and decreased visual acuity. Magnetic resonance imaging disclosed a tumor process of the skull base involving the sphenoid bone with its two left wings, the squamous part of the left temporal bone, and the left maxillary bone, associated with intracranial expansion, as well as a second, isolated mass in the temporal lobe (Fig. 1).

Direct nasofibroscopy with biopsy was performed. The histological results with immunohistochemistry were in favor of osteosarcoma with the following characteristics: 


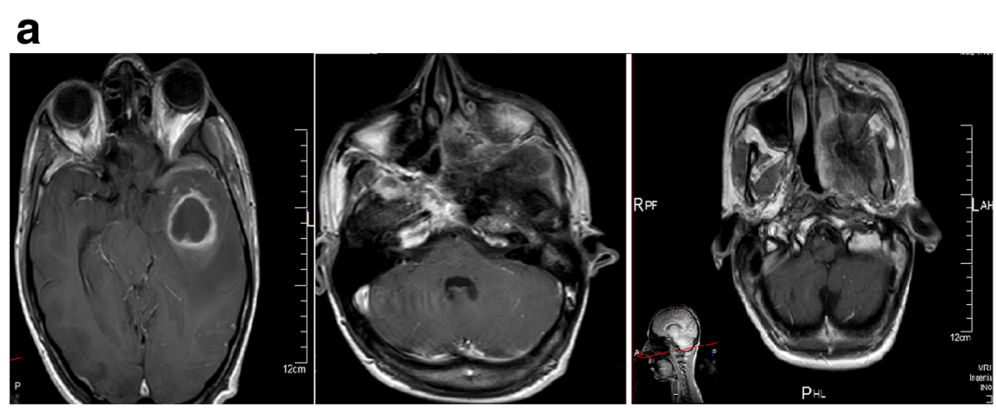

b
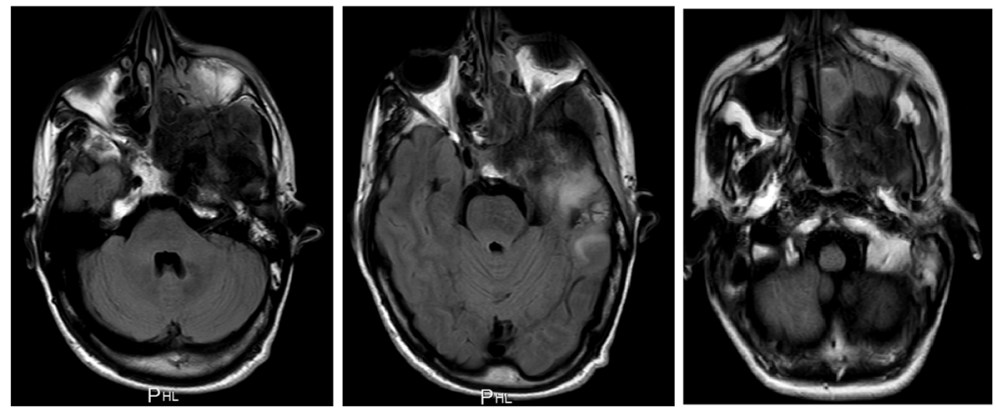

C
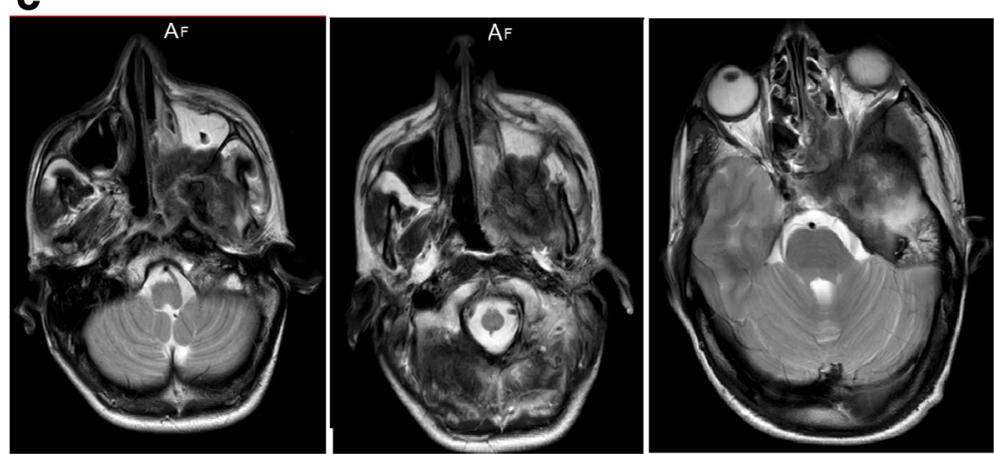

Fig. 1 Magnetic resonance imaging studies show a tumor process of the skull base involving the sphenoid bone with its two left wings, the squamous part of the left temporal bone, associated with intracranial expansion, as well as a second, isolated mass in the temporal lobe. a T1-weighted, gadolinium-enhanced axial magnetic resonance imaging scans. b T1-weighted, axial magnetic resonance imaging scans. c T2-weighted axial magnetic resonance imaging scans

spindle-cell neoplasm pleomorphism with badly limited cytoplasm, an irregular nucleus with frequent atypical mitoses, and an associated osteoid matrix. The results of immunohistochemistry with anti-AE1/AE3, anti-endomysial antibodies, and anti-CD34/CD31 were negative (Fig. 2).

A complete search for distant metastasis by positron emission tomography and by enhanced computed tomography of the chest, abdomen, and pelvis produced no results. We reviewed the initial pathology and documentation outlining the patient's original radiation therapy and confirmed that the tumor developed in the previously irradiated field. The tumor was deemed unresectable, and further radiation therapy was not advised. The patient was started on chemotherapy consisting of four cycles of ifosfamide, cisplatin, and doxorubicin, to be followed by four planned cycles of doxorubicin and ifosfamide. A physical evaluation after the second cycle revealed improvement of clinical signs, but after this initial remission, the patient's condition deteriorated, and he died 1 month after his third cycle of chemotherapy.

\section{Discussion}

Radiation therapy for head and neck cancer is a wellaccepted modality of treatment. It is a standard treatment for carcinoma of the nasopharynx. However, as with all treatment modalities, there are short- and longterm morbidities and occasionally mortalities. One of the most dreaded complications of radiation therapy is the formation of new malignancies. Although difficult to estimate, the incidence of radiation-induced tumors is extremely low [3]. The most frequent radiation-induced tumors are fibrosarcoma and osteosarcoma. Sarcomatous 


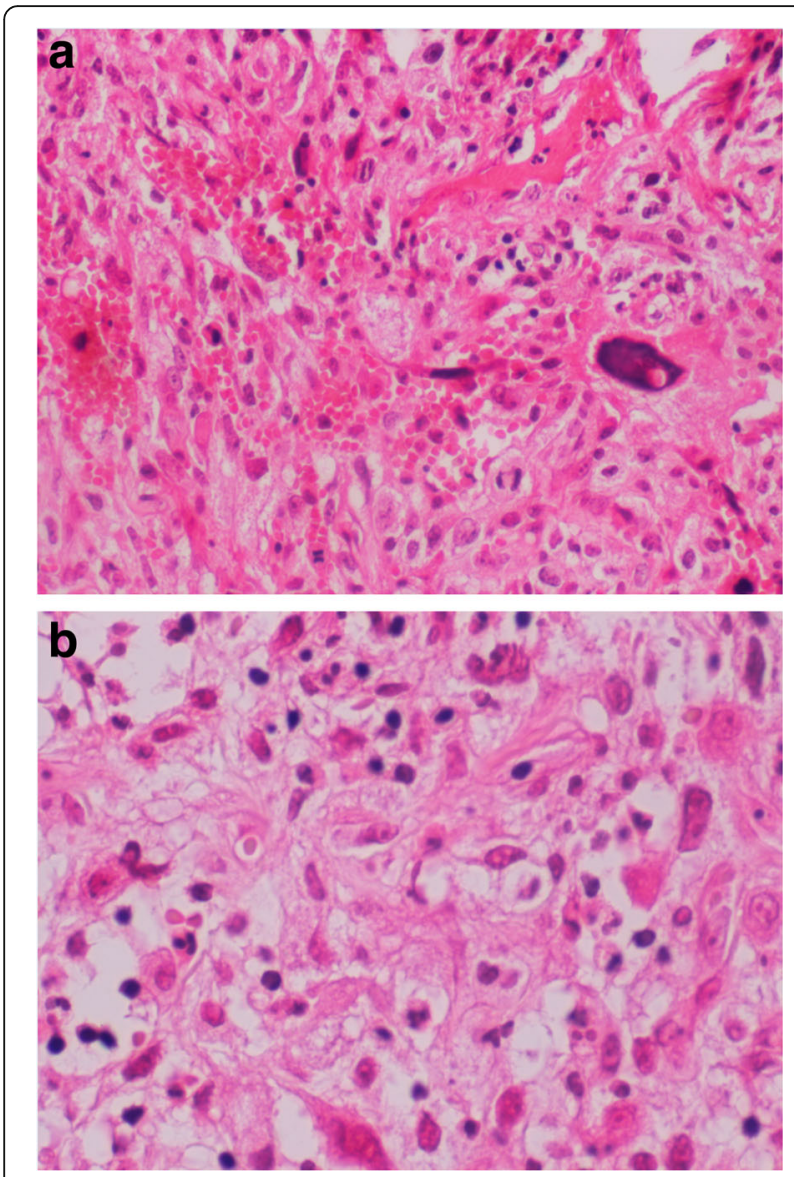

Fig. $\mathbf{2}$ a and $\mathbf{b}$ High-grade osteosarcoma with spindle-cell pleomorphic neoplasm, badly limited cytoplasm, and osteoid matrix. Original magnification $\times 20(\mathbf{a})$ and $\times 40(\mathbf{b})$

tumors account for most radiation-induced neoplasms involving the head and neck, and most occur in the facial skeleton. Very few involve the skull base [4-7]. Postirradiation osteosarcomas are rare, accounting for 3-6\% of all cases of osteosarcoma and $0.01-0.03 \%$ of all irradiated patients $[1,2]$. The incidence of radiation-induced tumors is increasing in the oncology population as a result of increased survival through the development of cancer treatment [8]. Cahan et al. described the following criteria for radiation-induced sarcoma: (1) The initial and secondary neoplasms are of significantly different histological types; (2) the secondary neoplasm must arise within the irradiated area; (3) there must be a long latency period after radiation ( $>5$ years); and (4) all sarcomas must be proven histologically [9]. Our patient fulfilled all these conditions, and the diagnosis of radiation-induced osteosarcoma was thus established.

The pathogenesis of postirradiation sarcoma is unknown. Various predisposing factors have been suggested: radiation dose, age of the patient at radiation exposure, association with chemotherapy, and genetic predisposition
[10]. Documentation of new mutations in genes implicated in malignant transformation after radiation therapy, such as the $p 53$ and retinoblastoma tumor suppressor genes, further supports induction of malignancy [11], suggesting that loss of these tumor suppressor genes plays a role in the development of these lesions $[12,13]$. Friend et al. proposed a link between retinoblastomas and osteosarcomas [14], and Patel et al. reported 2 of 16 patients who had retinoblastoma as the original lesion, for which the patients received radiation [15].

The latency period specified by Cahan et al. is more than 5 years. Since publication of their report, there have been some reports of patients developing radiationinduced sarcomas with shorter latency periods (as short as 2 years) [15-18]. Laskin et al. [19] reported a link between shorter latency periods and worse outcomes with radiation-induced soft tissue sarcomas, but this relationship has not been further substantiated in the literature. Patel et al. did not find any significant correlation between latency period and survival [15]. It is believed that the mean latency is inversely proportional to the dose received in radiotherapy. However, some authors indicate that the inverse relationship between dose and latency applies only to very high doses [20-22]. Other authors have noted that the latency period ranged from 3.5 to 33 years (median 10 years) [23]. In our patient, the tumor appeared 11 years after radiation.

Our review of skull base radiation-induced osteosarcoma cases revealed that the most common primary tumor for which radiation was initially received is pituitary adenoma. We found no case of radiation-induced osteosarcoma in skull base after radiotherapy for nasopharyngeal carcinoma. Otherwise, the anatomic site of the sarcoma has important implications for treatment and outcome. Reports detailing radiation-induced sarcoma in patients who were treated for head and neck cancer, particularly for nasopharyngeal carcinoma, are relatively few and limited to case reports and a few small case series $[6,24,25]$.

Mian et al. reported a series of 53 patients who developed radiation-induced malignancies after radiotherapy for nasopharyngeal carcinoma between 1964 and 2003. Fibrosarcoma was the most frequent histologic type at $41.5 \%$ (22 cases), followed by osteosarcoma at $22.6 \%$ (12 cases), without any being located in the skull base [25]. Malone et al. reported 35 cases of second malignant tumors after treatment of nasopharyngeal carcinoma. Ten cases of osteosarcoma were found, also without any located in the skull base [26]. Radiation-induced sarcoma in patients who were treated for head and neck cancer most often occurs in the facial skeleton; very few involve the skull base [5, 11, 25-27].

Complete surgical excision is the treatment of choice for radiation-induced osteosarcoma, although this can be 
Table 1 Characteristics of various published cases of skull base radiation-induced osteosarcoma

\begin{tabular}{|c|c|c|c|c|c|c|c|}
\hline First author (year) [reference] & $\begin{array}{l}\text { Age in } \\
\text { years/sex }\end{array}$ & Primary tumor & $\begin{array}{l}\text { Radiation } \\
\text { dose (Gy) }\end{array}$ & $\begin{array}{l}\text { Latency } \\
\text { (years) }\end{array}$ & Site of radiation-induced osteosarcoma & Treatment & Survival period \\
\hline Amine (1976) [32] & $16 / F$ & Pituitary adenoma & 51.0 & 10 & Sella & Radiation & 5 weeks \\
\hline Tanaka (1989) [33] & $57 / M$ & Craniopharyngioma & 110 & 15 & Sphenoid wing & Embolization surgery & 2 weeks \\
\hline Salvati (1994) [34] & $45 / M$ & Pituitary adenoma & 44 & 12 & Sphenoid & Radiation (50 Gy) & 16 months \\
\hline Gnanalingham (2002) [35] & $67 / F$ & Pituitary adenoma & 52 & 14 & Sella & Surgery & - \\
\hline Hansen (2003) [36] & $39 / M$ & Pituitary adenoma & 52 & 22 & Sella, clivus & Surgery & Short \\
\hline Bembo (2004) [37] & 45 & Pituitary adenoma & 46 & 5 & Sella & Surgery & 7 weeks \\
\hline Patel (2011) [15] & 44 & Craniopharyngioma & 60 & 9 & Sphenoid-ethmoid sinus & Chemotherapy & 16 months \\
\hline Yamada (2012) [38] & $75 / F$ & Pituitary adenoma & 50 & 20 & Sphenoid sinus & Cyberknife surgery, chemotherapy & 24 months \\
\hline \multirow[t]{9}{*}{ Patel (2011) [15] } & $54 / \mathrm{M}$ & Maxillary and adenoid cystic carcinoma & 60 & 12 & Sphenoid, frontal and temporal bone & Surgery, chemotherapy & 13 months \\
\hline & $63 / M$ & Squamous cell carcinoma, nasal cavity & - & 4.5 & Palate + maxillary sinus & Surgery, chemotherapy & 47 months \\
\hline & $50 / M$ & Squamous cell carcinoma, nasal cavity & - & 14 & Infratemporal fossa & Surgery, chemotherapy & 17 years \\
\hline & $44 / F$ & Craniopharyngioma & - & 9 & Sphenoidal, ethmoidal bone & Chemotherapy & 18 months \\
\hline & $15 / M$ & Retinoblastoma & - & 15 & Zygoma & Surgery, chemotherapy & 62 months \\
\hline & $22 / \mathrm{M}$ & Retinoblastoma & - & 20 & Ethmoid + maxillary sinus & Surgery, chemotherapy & - \\
\hline & $10 / \mathrm{M}$ & Rhabdomyosarcoma & - & 6.75 & Mastoid + jugular foramen & Surgery, chemotherapy, radiation & 29 months \\
\hline & $31 / M$ & Rhabdomyosarcoma & 60 & 18 & Palate + infratemporal fossa & Surgery, chemotherapy & 143 months \\
\hline & $26 / M$ & Retinoblastoma & 35 & 25 & & Surgery, chemotherapy & 41 months \\
\hline Hansen (2003) [36] & $29 / M$ & Pituitary adenoma & $5000 \mathrm{rad}$ & 22 & Sphenoid, frontal clivus & Chemotherapy & Very short \\
\hline Patel (2014) [39] & $52 / \mathrm{M}$ & Craniopharyngioma & 50 & 22 & Sella + clivus & Surgery & 1 month \\
\hline Our patient & $28 / \mathrm{M}$ & Nasopharynx carcinoma & 70 & 11 & Sphenoid + maxillary bone & Chemotherapy & 6 months \\
\hline
\end{tabular}


difficult when there is skull base involvement. The benefit of adjuvant therapy has not been established on a previously irradiated field [8]. For patients with unresectable tumors, radiotherapy and/or chemotherapy are acceptable alternatives. Some reports described the effectiveness of chemotherapy, with variable results, using doxorubicin, ifosfamide, methotrexate, carboplatin, vincristine, or etoposide [28-30], but a definitive protocol has not been established.

Radiation-induced osteosarcomas are considered to be highly aggressive lesions. Local recurrence for primary osteosarcomas of the head and neck has been reported to be $22 \%$ [31], and $86 \%$ for radiation-induced osteosarcoma [15].

Patel et al. [15] compared a skull base radiationinduced osteosarcoma group with a calvarial radiationinduced osteosarcoma group and found that the median progression-free survival intervals were 9.5 months and 19 months, respectively $(P=0.6322)$. These differences were not statistically significant. The median overall survival times of patients with radiation-induced osteosarcoma of the skull base was 41 months (Table 1).

The 5-year disease-free survival time for patients with radiation-induced osteosarcoma has been reported to be $17 \%$ [10], as opposed to $70 \%$ in patients with primary osteosarcomas of the head and neck [31].

\section{Conclusions}

Radiation-induced osteosarcoma of the skull base after treatment of nasopharyngeal carcinoma is a very rare but very aggressive complication with a poor prognosis. The overall incidence seems quite low and should not change current practice; however, regular follow-up of treated patients should be considered. Complete surgical excision, if possible, can optimize survival of these patients when the tumor is detected at an early stage.

\section{Acknowledgements}

Not applicable.

\section{Funding}

Not applicable.

\section{Availability of data and materials}

Data sharing is not applicable to this article, because no datasets were generated or analyzed during the study.

\section{Authors' contributions}

YE is the corresponding author. HL, AT, TK, and NB contributed to management of the patient and acquisition of data, revised the manuscript, approved the version to be published, and agree to be accountable for all aspects of the work. All authors read and approved the final manuscript.

\section{Competing interests}

The authors declare that they have no competing interests.

\section{Consent for publication}

Written informed consent was obtained from the patient for publication of this case report and any accompanying images. A copy of the written consent is available for review by the Editor-in-Chief of this journal.
Ethics approval and consent to participate

Not applicable.

Received: 25 July 2016 Accepted: 23 October 2016

Published online: 01 December 2016

\section{References}

1. Goodman MA, McMaster JH. Primary osteosarcoma of the skull. Clin Orthop Relat Res. 1976;120:110-4.

2. Salvati M, Ciappetta P, Raco A. Osteosarcomas of the skull: clinical remarks on 19 cases. Cancer. 1993:71(7):2210-6.

3. Mark RJ, Poen J, Tran LM, Fu YS, Selch MT, Parker RG. Postirradiation sarcomas: a single-institution study and review of the literature. Cancer. 1994;73:2653-62.

4. Chang SM, Barker 2nd FG, Larson DA, Bollen AW, Prados MD. Sarcomas subsequent to cranial irradiation. Neurosurgery. 1995;36:685-90.

5. Mark RJ, Bailet JW, Poen J, Tran LM, Calcaterra TC, Abemayor E, et al. Postirradiation sarcoma of the head and neck. Cancer. 1993;72:887-93.

6. Patel SG, See AC, Williamson PA, Archer DJ, Evans PH. Radiation induced sarcoma of the head and neck. Head Neck. 1999:21:346-54.

7. Lee YY, Van Tassel P, Nauert C, Raymond AK, Edeiken J. Craniofacial osteosarcomas: plain film, CT, and MR findings in 46 cases. AJR Am J Roentgenol. 1988;150:1397-402.

8. Prakash O, Varghese BT, Mathews A, Nayak N, Ramchandran K, Pandey M. Radiation induced osteogenic sarcoma of the maxilla. World J Surg Oncol. 2005;3:49.

9. Cahan WG, Woodward HQ, Higinbotham NL, Stewart FW, Coley BL. Sarcoma arising in irradiated bone: report of eleven cases. Cancer. 1948;1:3-29.

10. Chabchoub I, Gharbi O, Remadi S, Limem S, Trabelsi A, Hochlef M, et al. Postirradiation osteosarcoma of the maxilla: a case report and current review of literature. J Oncol. 2009;2009:876138.

11. Brachman DG, Hallahan DE, Beckett MA, Yandell DW, Weichselbaum RR. p53 gene mutations and abnormal retinoblastoma protein in radiation-induced human sarcomas. Cancer Res. 1991;51:6393-6.

12. Gonin-Laurent N, Hadj-Hamou NS, Vogt N, Houdayer C, Gauthiers-Villars M, Dehainault C, et al. RB1 and TP53 pathways in radiation-induced sarcomas. Oncogene. 2007;26:6106-12.

13. Gonin-Laurent N, Gibaud A, Huygue M, Lefèvre SH, Le Bras M, Chauveinc L, et al. Specific TP53 mutation pattern in radiation-induced sarcomas. Carcinogenesis. 2006;27:1266-72.

14. Friend SH, Bernards R, Rogelj S, Weinberg RA, Rapaport JM, Albert DM, et al. A human DNA segment with properties of the gene that predisposes to retinoblastoma and osteosarcoma. Nature. 1986;323:643-6.

15. Patel AJ, Rao VY, Fox BD, Suki D, Wildrick DM, Sawaya R, et al. Radiationinduced osteosarcomas of the calvarium and skull base. Cancer. 2011;117: 2120-6.

16. Matsuyama A, Yonemitsu N, Hayashida S, Watanabe K, Sugihara H, Inokuchi A. Case of postradiation osteosarcoma with a short latency period of 3 years. Pathol Int. 2003:53:46-50

17. Sale KA, Wallace DI, Girod DA, Tsue TT. Radiation-induced malignancy of the head and neck. Otolaryngol Head Neck Surg. 2004;131:643-5.

18. Murray EM, Werner D, Greeff EA, Taylor DA. Postradiation sarcomas: 20 cases and a literature review. Int J Radiat Oncol Biol Phys. 1999;45:951-61.

19. Laskin WB, Silverman TA, Enzinger FM. Postradiation soft tissue sarcomas: an analysis of 53 cases. Cancer. 1988;62:2330-40.

20. Finkel AJ, Miller CE, Hasterlik RJ. Radium-induced malignant tumors in man. In: Mays CW, Jee WSS, Lloyd RD, editors. Delayed effects of bone-seeking radionuclides. Salt Lake City: University of Utah Press; 1969. p. 195-225.

21. Rushton MA, Owen M, Holgate W, Vaughan J. The relation of radiation dose to radiation damage in the mandible of weanling rabbits. Arch Oral Biol. 1961;3:235-46.

22. Alzahrani M, Robier A, Pointreau Y, Bakhos D. A rare case of radiationinduced osteosarcoma of the ethmoid sinus. Case Rep Otolaryngol. 2011; 2011:786202.

23. Huvos AG. Bone tumors: diagnosis, treatment and prognosis. 2nd ed. Philadelphia: W.B. Saunders; 1991.

24. Jones AS, Morar P, Phillips DE, Field JK, Husband D, Helliwell TR. Second primary tumors in patients with head and neck squamous cell carcinoma. Cancer. 1995;75:1343-53. 
25. Xi M, Liu MZ, Wang HX, Cai L, Zhang L, Xie CF, et al. Radiation-induced sarcoma in patients with nasopharyngeal carcinoma: a single-institution study. Cancer. 2010;116:5479-86.

26. Malone JP, Levin RJ. Second malignant tumors after treatment of nasopharyngeal carcinoma: four case reports and literature review. Skull Base. 2002;12:87-91.

27. Huvos AG, Woodard HQ. Postradiation sarcomas of bone. Health Phys. 1988; 55:631-6.

28. Wiklund TA, Blomqvist CP, Räty J, Elomaa I, Rissanen P, Miettinen M. Postirradiation sarcoma: analysis of a nationwide cancer registry material. Cancer. 1991;68:524-31.

29. Sugita Y, Shigemori M, Miyagi J, Ochiai S, Lee S, Watanabe T, et al. Radiation-induced osteosarcoma of the calvaria - case report. Neurol Med Chir (Tokyo). 1992;32:32-5.

30. Carpentier AF, Chantelard JV, Henin D, Poisson M. Osteosarcoma following radiation treatment for meningioma: report of a case and effective treatment with chemotherapy. J Neurooncol. 1994;21:249-53.

31. Patel SG, Meyers P, Huvos AG, Wolden S, Singh B, Shaha AR, et al. Improved outcomes in patients with osteogenic sarcoma of the head and neck. Cancer. 2002;95:1495-503.

32. Amine AR, Sugar O. Suprasellar osteogenic sarcoma following radiation for pituitary adenoma: case report. J Neurosurg. 1976:44:88-91.

33. Tanaka S, Nishio S, Morioka T, Fukui M, Kitamura K, Hikita K. Radiationinduced osteosarcoma of the sphenoid bone. Neurosurgery. 1989;25:640-3.

34. Salvati M, Cervoni L, Ciappetta P, Raco A. Radiation-induced osteosarcomas of the skull: report of two cases and review of the literature. Clin Neurol Neurosurg. 1994;96:226-9.

35. Gnanalingham KK, Chakraborty A, Galloway M, Revesz T, Powell M. Osteosarcoma and fibrosarcoma caused by postoperative radiotherapy for a pituitary adenoma: case report. J Neurosurg. 2002;96:960-3.

36. Hansen MR, Moffat JC. Osteosarcoma of the skull base after radiation therapy in a patient with McCune-Albright syndrome: case report. Skull Base. 2003:13:79-83.

37. Bembo SA, Pasmantier R, Davis RP, Xiong Z, Weiss TE. Osteogenic sarcoma of the sella after radiation treatment of a pituitary adenoma. Endocr Pract. 2004;10:335-8

38. Yamada SM, Ishii Y, Yamada S, Kuribayashi S, Kumita S, Matsuno A. Advanced therapeutic strategy for radiation-induced osteosarcoma in the skull base: a case report and review. Radiat Oncol. 2012;7:136.

39. Patel RD, Gadgil NM, Khare M, Majethia N. Radiation-induced intracranial osteosarcoma: a case report. J Postgrad Med. 2014;60:218-9.

\section{Submit your next manuscript to BioMed Central and we will help you at every step:}

- We accept pre-submission inquiries

- Our selector tool helps you to find the most relevant journal

- We provide round the clock customer support

- Convenient online submission

- Thorough peer review

- Inclusion in PubMed and all major indexing services

- Maximum visibility for your research

Submit your manuscript at www.biomedcentral.com/submit 